Original article

https://www.journal-imab-bg.org

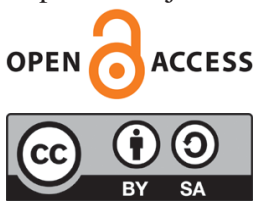

\title{
MEASUREMENT OF THE CERVICAL LENGTHIN 20-24WEEKS GESTATION, HISTORY OF PREVIOUS PRETERM LABORAND ASSESSMENT OF THE VAGINAL MICROFLORA FOR BACTERIAL VAGINOSIS IN THE FIRST TRIMESTER AS A POPULATIONAL SCREENING FOR PRETERM BIRTH
}

\author{
Ivan D. Ivanov \\ Department of Obstetrics and Gynecolgy, MHAT Trakia, Stara Zagora, Bulgaria.
}

\section{SUMMARY}

Preterm delivery (PTD) is a problem with a social significance, considering the fact, that it is a leading cause for perinatal complications and perinatal mortality and spending resources in healthcare and those who are born pretermhave a high risk for complications, chronic disability. The rate of preterm birth has not decreased in the last 50 years and continues to grow, despite the advances of the medical science and the understanding of the risk factors and the mechanisms leading to preterm birth. It is considered that one of the main reasons for that is the absence of a standard, easily applicable and effective screening protocol in routine antenatal care. The objective of this study is to evaluate the ability of the combination of the history of prior preterm birth, cervical length measurement in $20-24 \mathrm{wg}$ and the assessment of the vaginal microflora in the first trimester as a screening for spontaneous PTD. This was an observational and prospective study of 334 unselected pregnant women and data were collected aboutrisk factors, such as the history of previous PTD, conception method (spontaneous or after ART),etc. to estimate the prevalence and the significance of these factors and to define an algorithm to estimate the individual risk of PTD. The combination of the history of prior PTD and second trimester cervical length measurement allows estimation of the risk for PTD. The proposed screening is applicable in the routine practice, doesn't require additional resources, and it could be expected that its introduction would lead to lowering of the burden of PTD (neonatal morbidity, mortality, etc.).

Keywords: Cervical length, preterm birth, screening

\section{INTRODUCTION}

PTB is a significant problem in healthcare and in obstetrics particularly, which rate has not decreased instead of the development of medical scienceand the understanding of the factors leading to preterm delivery (PTD). One of the leading causes of that is the lack of an efficient screening to identify accurately enough the group of pregnant women which are at increased risk for preterm delivery. Series of studies in the recent years estimated many risk factors for PTD, such as previ- ous PTD or late spontaneous abortion (after 18 weeks gestation) [1], multiple fetal pregnancy, pregnancy after assisted reproduction, evidence of colonization or infection of the vaginawith bacteria, etc. and the ability of the measurement of the cervical length to predict the risk of PTD [2, 3, 4]. Other series of studiesestimated the ability of certain interventions to influence the above mentioned risk factors. These are the vaginal progesteron, cervical cerclage, antibiotics, etc. $[5,6,7,8,9$, 10]. These two groups of studiessubstantiated the further look for an effective antenatal populational screening for PTD. Currently, there is no officially accepted screening for PTD in our countryand the most commonly used approach is the obstetric history for previous PTD and the digital assessment of the cervix in symptomatic women. The digital assessment of the cervix is inadequate, subjectiveand with a significant variability for screening purposes and for differentiating false labor in symptomatic women. The cervix dilates starting from the internal orifice, which is inaccessible for digital examination when the outer orifice is closed. Using a digital examination, we could assess the characteristics of portiovaginalis, but the supravaginal part of the cervixis difficult to assess. PTD is a heterogeneous syndrome where many different factors interfere at different levels in the pathogenesis of the initiation of labor with a common end-result delivery before completion of 36 weeks gestation $(\mathrm{wg})[11,12,13,14]$. The different characteristics of the different risk factors and the unclear mechanism of the initiation of labor make it difficult to elaborate standard, unified and effective screening and as a result of that the prophylactic, diagnostic and therapeutic measures are ineffective. There is a necessity of reliable and accessible methods of screening in the context of routine antenatal cares in order to influence the risk of PTD and to reduce and to decrease the rate of PTD and the associated morbidity and mortality.

Methods of screening such as measurement of the uterine cervix, obstetric history, the assessment of the vaginal microflora and the application of biological marker tests predict PTD with a certain efficacy. Models combining the above mentioned methods produce better predictivity than either method alone and secure better specificity, sensitivity and predictive values of the screening [15]. 


\section{Aim of the study}

The aim of the current work is to study the capability of the combination of measurement of the uterine cervix in the second trimester of the pregnancy, taking obstetric history for previous PTD or late (after $18 \mathrm{w} . \mathrm{g}$.) miscarriage and the assessment of the vaginal microflora to estimate the risk of spontaneous PTD and to propose easilyaccessible screening algorithm for populational screening for PTD in the routine antenatal cares.

\section{MATERIALS AND METHODS}

This is a prospective observational study conducted for a period of five yearson 334 unselected pregnant women during the routine antenatal cares. It was offered transvaginalsonography for measurement of the cervical length between 20 and $24 \mathrm{wg}$, microbiological assessment of the vaginal microflora in the first trimester of pregnancy [16] and history was taken for previous PTD. The outcome was preterm delivery before completion of 37 wgand was further stratified on extreme $(<28 \mathrm{wg})$, early $(28-30 \mathrm{wg})$, moderate $(31-33 \mathrm{wg})$ and mild $(34-36 \mathrm{wg})$. Logistic regression analysis was usedin order to produce a model for estimation of the risk for PTD.

The gestational age was determined using the last menstrual period and confirmed by CRL in the first trimester.Measurement of the cervical length was performed using the standards of the Fetal Medicine Foundation.The measurements were taken for at least three minutes, and the cervix was measured at least, and the shortest measurement was recorded. Using transvaginalsonography, the probe is carefully introducedinto the anterior fornix until an optimal image is observed and then slightly withdrawnup to the moment of disappearance of the achieved optimal image (Fig. 1). The cervix is visualized sagitally and the cervical canal in all its length from inner to the outer orifice. Endocervical mucosa is a marker for the real position of the internal orifice. The cervix should occupy $50-70 \%$ of the image. It is necessary to measure the cervical length and to assess the condition of the internal orifice for a period of 3-5 minutes in order to take into account the influence of uterine contractions.

Fig. 1. Normal cervix. The whole cervical canal is seen, curved, with no funneling.

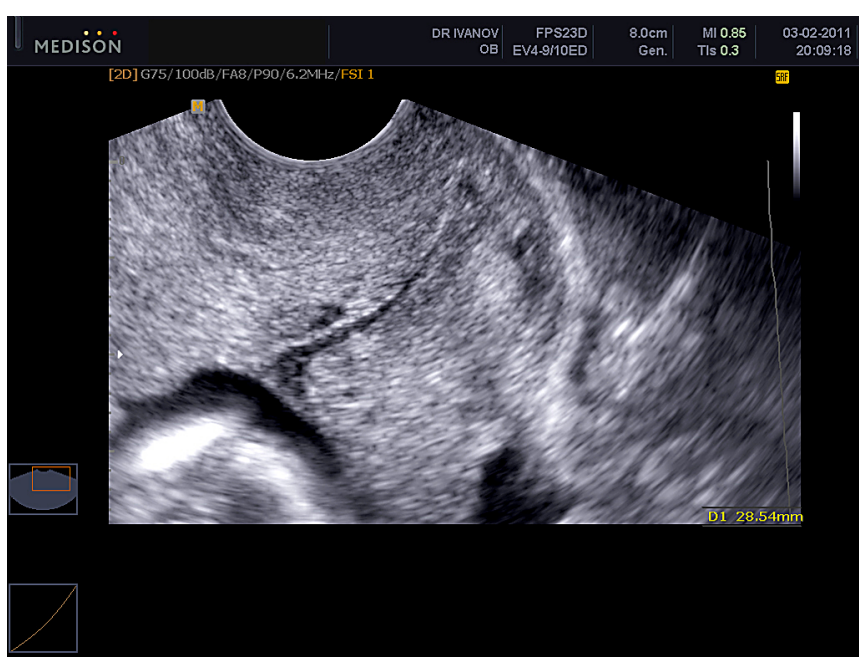

As a short cervix is accepted a length below $25 \mathrm{~mm}$ (10th centile) as we also look for funnelling and debris (sludge) (Table 1 and 2).

Table 1. Cervical length in the 2nd trimester and the risk of PTD

\begin{tabular}{|l|l|}
\hline $60-20 \mathrm{~mm}$ & $\sim 5 \%$ \\
\hline $15 \mathrm{~mm}$ & $10 \%$ \\
\hline$<15 \mathrm{~mm}$ & The risk increases exponentially \\
\hline
\end{tabular}

Table 2. Cervical length in the 2 nd trimester of the pregnancy

\begin{tabular}{|c|c|}
\hline $2,0 \mathrm{~cm}$ & 5 th percentile \\
\hline $2,5 \mathrm{~cm}$ & 10th percentile \\
\hline $3,5 \mathrm{~cm}$ & 50 th percentile \\
\hline $4,5 \mathrm{~cm}$ & 90th percentile \\
\hline
\end{tabular}

The presence of intra-amnial cervical debrisin transvaginalsonography is considered to carry a high-risk for PTD before $34 \mathrm{wg}$ and a high risk for delivery in the next two weeks. Intra-amnial debris is an independent risk factor for PPROM and PTD. The combination of cervical length under $15 \mathrm{mmand}$ cervical debrisis associated with a very high rate of PTD (before 34wg - 75\%) [17, 18].

Fig. 2. Short cervix and cervical debris (sludge)

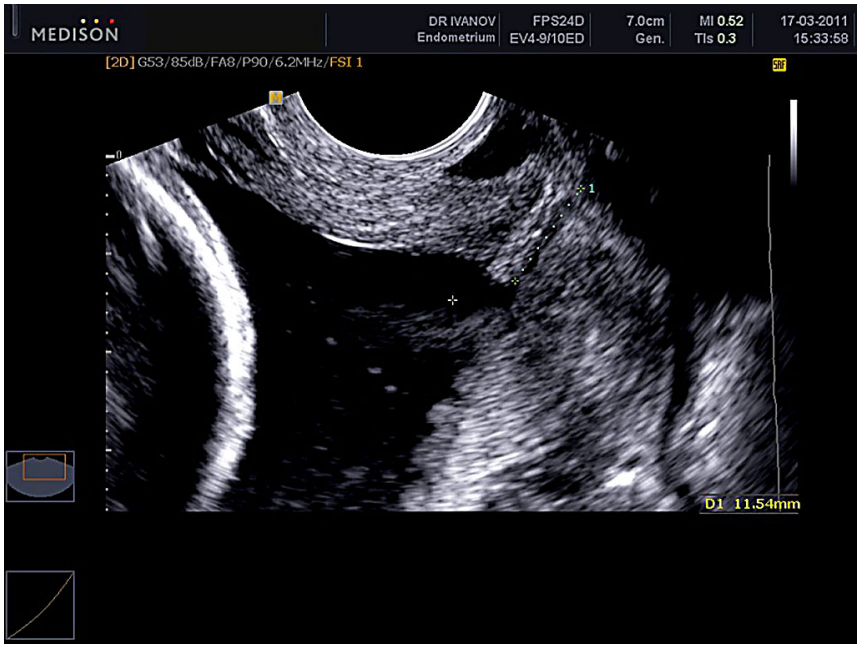

The presence of fetalfibronectin in cervico-vaginal secretions after $22 \mathrm{wg}$ is associated with a high risk of PTD $[19,20]$. In our study, a test for fetalfibronectin was used in selected cases:

- Symptomatic with short cervix or previous PTD.

- Short cervix and cervical debris (sludge).

- Bacterial vaginosis.

- Multiple fetalpregnancy.

Inclusion of biological markers would improve the predictivity of the screening, but their application as a screening tool is limited because it would make the screen- 
ing procedure too expensive. Their application is useful in selected cases considered a high risk for PTD to improve predictivity and to differentiate "false" and "true" labor on cases with threatening PTD.

In patients considered to be a high risk for PTD measures to reduce the incidence of PTD were proposed, such as vaginal progesterone, cerclage, antibiotics etc. All pregnant women in the study gave their informed consent. According to the obstetric history, the pregnant women were divided into two groups - within their first pregnancyor having their first baby at termand the second group with previous PTD or late miscarriage after $18 \mathrm{wg}$. The outcome data (date and gestational age at birth) were recorded and confirmed during post-natal visits.

\section{RESULTS}

In order to clarify the factors associated with PTD and to quantify their impact, we performed a binary logistic regression analysis. The frequency of PTD in the inves- tigated groupwas $12,87 \%$ and $6,98 \%$ - extreme, early $6,98 \%$, moderate $-20,9 \%$, mild $-65,1 \%$.

As potentialrisk factors were tested:
A. Risk factors
1. Previous PTD
2. First trimester bacterial vaginosis
3. Cervical length $<25 \mathrm{~mm}$
4. Fetalfibronectine in cervico-vaginal secretions
5. Symptoms of threatening PTD
6. Multifetal pregnancy
7. Pregnancy after ART
B. Preventive factors
1. Vaginal progesteron
2. Cerclage

Within the studied population of pregnant women, we found that the overall prevalence of risk factors was $46.5 \%$. In $15 \%$, there was more than one risk factor. (Table. 3 )

Table 3. The rate of risk factors and the corresponding relative risk of PTL.

\begin{tabular}{|l|c|c|}
\hline Risk factor & Rate \% & Relative PTL risk \% \\
\hline Previous PTL & 1,5 & 40 \\
\hline Bacterial vaginosis & 4,8 & 12,5 \\
\hline Short cervix & 6,9 & 43,5 \\
\hline Pregnancy after ART & 9,9 & 24 \\
\hline Multiple fetal pregnancy & 3,9 & 46 \\
\hline
\end{tabular}
say that:

After analysis of the studied risk factors, we could

- The risk of PTL was higher with previous PTL (either spontaneous or indicated).

- The risk of PTL was higher in pregnancies after ART, including single fetus pregnancies.

- The risk of PTL was higher in multiple fetal pregnancies.

- The higher risk of PPROM and spontaneous PTL in pregnancies with bacterial vaginosiswas not demonstrated in our study probably because of the low rate of the bacterial vaginosis within the studied population.

- The risk of PTL was higher in pregnant women with symptoms of threatening PTL.

- The risk of PTL was higher in pregnant women with a short cervix (less than $25 \mathrm{~mm}$ in transvaginalsono- graphy).

- The FFN test allows discriminating amongst the screen positive those women who are at risk for delivery in the next two weeks and those with "real" threatening PTL.

We found that in the absence of the studied risk factors the baseline probability for PTL is $8,8 \%$; The risk of PTL significantly correlates with the trans-vaginally measured short cervical length $(<25 \mathrm{~mm})$ in the second trimester ad also with the presence of multiple fetal pregnancy. Cervical length $<25 \mathrm{~mm}-43,4 \%$; Multiple fetal pregnancy around $46,2 \%$.

There are available interventions in screen positive pregnant women influencing the PTL risk with certain efficacy, such as vaginal progesterone, cerclage, antibiotics, etc.

Table 4. PTL risk and 95\% CI of the studied risk factors

\begin{tabular}{|c|c|c|c|c|c|c|c|c|c|}
\hline \multirow{3}{*}{ Factor } & \multirow{3}{*}{ Correlation } & \multicolumn{3}{|c|}{ Individual } & \multicolumn{4}{|c|}{ Group } & \multirow{3}{*}{$\mathrm{p}$} \\
\hline & & \multirow[b]{2}{*}{ OR } & \multicolumn{2}{|c|}{$95 \% \mathrm{CI}$} & \multirow[b]{2}{*}{$\mathrm{p}$} & \multirow[b]{2}{*}{ OR } & \multicolumn{2}{|c|}{$95 \% \mathrm{CI}$} & \\
\hline & & & $\begin{array}{c}\text { Lower } \\
\text { limit }\end{array}$ & $\begin{array}{c}\text { Upper } \\
\text { limit }\end{array}$ & & & $\begin{array}{c}\text { Lower } \\
\text { limit }\end{array}$ & $\begin{array}{c}\text { Upper } \\
\text { limit }\end{array}$ & \\
\hline Previous PTL & Yes/no & 4,683 & 0,760 & 28,869 & 0,096 & & & & \\
\hline Bacterial vaginosis & Yes/no & 0,965 & 0,212 & 4,402 & 0,963 & & & & \\
\hline Short $\mathrm{CL}<25 \mathrm{~mm}$ & Yes/no & 6,635 & 2,692 & 16,351 & $<0,001$ & 7,959 & 3,180 & 19,919 & $<0,001$ \\
\hline Multiple fetal pregnancy & Yes/no & 6,579 & 2,098 & 20,633 & 0,001 & 8,868 & 2,774 & 28,355 & $<0,001$ \\
\hline
\end{tabular}




\begin{tabular}{|c|c|c|c|c|c|}
\hline $\begin{array}{l}\text { Threatening PTL } \\
\text { symptoms }\end{array}$ & Yes/no & 3,026 & 1,417 & 6,462 & 0,004 \\
\hline Pregnancy after ART & $\begin{array}{c}\text { ART/ } \\
\text { spontaneous } \\
\text { pregnancy }\end{array}$ & 2,423 & 1,014 & 5,787 & 0,046 \\
\hline Cerclage & Yes/no & 3,524 & 0,313 & 39,739 & 0,308 \\
\hline
\end{tabular}

\section{DISCUSSION}

Individually we found that:

- Previous PTL had 4,7 times higher risk of PTL, but the correlation of risks had borderline significance $(\mathrm{p}<0,1)$;

- Bacterial vaginosis in our study have not had a statistically significant influence on PTL riskprobably because of the low prevalence of bacterial vaginosis within the studied population;

- Cervical length less than $25 \mathrm{~mm}$ increases the risk of PTL 6,6 times;

- Multiple feltal pregnancy was found to have 6,6 times higher risk of PTL;

- Having symptoms of threatening PTL was associated with 3 times higher risk for PTL.

In order to estimate the combined influence of the risk factors which were found to be significant, we applied multiple binary logistic regression analysis. The results (Ta- ble. 5) showed that:

- In the final model remainedshort cervical length of less than $25 \mathrm{~mm}$ and multiplefetal pregnancy;

- This modelprovides correct classification in 87,3\% of cases;

- The influence of the short cervix $<25 \mathrm{~mm}$ increased 8 times, and multiple fetalpregnancy about 8,9 times.

\section{Assessment of the individual risk for PTL}

Based on the binary logistic regression analysispredictive regression equation was generated in order to assess the individual PTL risk:

Individual risk $=8,8 \%+($ Cervical length $<25 \mathrm{~mm}) *$ $43,4 \%+$ Multiple fetal pregnancy* 46,2\%

It's obvious from this model that:

- In the absence of the studied risk factors the probability for PTL 8,8\%;

- Cervical length $<25 \mathrm{~mm}-43,4 \%$;

- Multiple fetal pregnancy $-46,2 \%$.

Table 5. Individual risk for prematurity

\begin{tabular}{|c|c|c|c|c|c|}
\hline \multirow[b]{2}{*}{ Risk factors } & \multicolumn{4}{|c|}{ Individual risk for prematurity $(\%)$} & \multirow[b]{2}{*}{ Overal } \\
\hline & Extreme & Early & Moderate & Mild & \\
\hline None & 0,7 & 1,0 & 2,4 & 4,7 & 8,8 \\
\hline Cervical length $<25 \mathrm{~mm}$ & 0 & 0 & 4,3 & 39,1 & 43,4 \\
\hline Multi-fetal pregnancy & 7,7 & 0 & 7,7 & 30,8 & 46,2 \\
\hline
\end{tabular}

- With the highest percentage $(91 \%)$ of correct answers is FFN test, followed by the history of previous PTD - 87\%. The lowest $(84 \%)$ - bacterial vaginosis;

- The highest sensitivity test $(75 \%)-$ FFN test, followed by the cervical length $<25 \mathrm{~mm}-24 \%$. And the lowest sensitivity - $(5 \%)$ for previous PTD and bacterial vaginosis;

- The highest specificity - $(100 \%)$ again the FFN test, followed by previous PTL with $99 \%$. The lowest specificity $(95 \%)$ is for bacterial vaginosis;

- All the tests presented higher negative than positive predictivity.

Table 6. Validation criteria of the tests

\begin{tabular}{lccccc}
\hline & $\begin{array}{c}\text { Sensitivity } \\
(\boldsymbol{\%})\end{array}$ & $\begin{array}{c}\text { Specificity } \\
(\boldsymbol{\%})\end{array}$ & $\begin{array}{c}\text { Positive predictive } \\
\text { value }(\boldsymbol{\%})\end{array}$ & $\begin{array}{c}\text { Negative predictive } \\
\text { value }(\boldsymbol{\%})\end{array}$ & $\begin{array}{c}\text { Precision } \\
(\boldsymbol{\%})\end{array}$ \\
\hline Previous PTD & 5 & 99 & 40 & 88 & 87 \\
\hline Bacterial vaginosis & 5 & 95 & 13 & 87 & 84 \\
\hline Cervical length<25mm & 24 & 96 & 43 & 80 & 86 \\
\hline Multifetal pregnancy & 14 & 98 & 46 & 88 & 87 \\
\hline FFN test & 75 & 100 & 100 & 91 \\
\hline
\end{tabular}

We have found that there was a significant correlationbetween the cervical lengthin the second trimester of the pregnancy and the risk of prematurity. 


\section{CONCLUSION}

In our study, $1,5 \%$ of the pregnant women have a history for previous PTD or late miscarriage (depending on the definitions), and they contributed for $5 \%$ of the preterm deliveries. The recurrence risk is inversely related to the gestational age and in straight relation to their number. Screening based only on obstetric history would be very inefficient. Combined screening, including obstetric history, second trimester cervical length measurement and vaginal microbiology would have higher detection rates. For $10 \%$ screening positivity, this model detects $33 \%$ of preterm where we could intervene and improve the outcome. Adding factors such as - multiple fetalpregnancy, pregnancy after ART and symptoms of threatening PTD increases the detection rates up to $40 \%$.

From the above modalities, the best prediction is assured by the cervical length measurement in the second trimester of the pregnancy (20-24w.g.). The combined screening model has its best efficacy for the highest degrees of prematurity with $7-10 \%$ screen positivity and the corresponding detection rates- $60-80 \%$. Detection rates for late (after 34w.g.) are $30 \%$.

The risk assessment needs to be modified for multiple fetal pregnancies and for pregnancies after ART and could also be stratified for the different degrees of prematurity.

Adding the results from vaginal microbiology didn't show effect in our study probably because of the lower rates within the studied population - only 4,8\% compared with data from other studies with a population prevalence of up to $20 \%$. The application of vaginal progesterone decreases the incidence of spontaneous PTDs in pregnant women with a history of previous PTD with $25 \%$ and in those with short cervix $25 \mathrm{~mm}$ with $35-40 \%$ and justifies the introduction of a populational screening for PTD. This would bring financial, healthcare and social benefits considering the fact that the PTB is the leading cause of neonatal morbidity and mortality and its late sequels.

It is necessary to define accurately enoughscreening procedures and guidelines in the context of antenatal cares: screening for congenital (including chromosomal) anomalies, preeclampsia screening, gestational diabetes screening, preterm delivery screening etc.

Clarification of these procedures and adequate definition of high-risk groups and application of the procedures influencing the risk and improving outcomesare amongst the basic challenges in modern obstetrics. It is necessary to elaborate and apply guidelines and algorithms for everyday practice.

Measurement of the cervical lengthand combining it with obstetric historycould be applied as a baseline population screening for PTD. The results need to be modified for multiple fetal pregnancy and pregnancy after ART. Adding biological markers would increase the predictivity of the screening, but on the other hand, would also raise the costs. That's why their application is considered in selected patients with threatening preterm birth and in those with a short cervix.

Applying this accessible, simple and low-cost screening procedure and the application of interventions influencing the risk has the potential to improve the current situation with PTDs and to reduce the burden of its consequences.

\section{REFERENCES:}

1. Iams JD, Berghella V. Care for women with prior preterm birth. Am J Obstet Gynecol. 2010 Aug;203(2):89100. [PubMed] [Crossref]

2. Heath VC, Southall TR, Souka AP, Elisseou A, Nicolaides KH. Cervical length at 23 weeks of gestation: prediction of spontaneous preterm delivery. Ultrasound Obstet Gynecol. 1998 Nov; 12(5):312-7. [PubMed] [Crossref]

3. To MS, Skentou CA, Royston P, Yu CK, Nicolaides KH. Prediction of patient-specific risk of early preterm delivery using maternal history and sonographic measurement of cervical length: a population-based prospective study. Ultrasound Obstet Gynecol. 2006; 27(4):362-367. [PubMed]

4. Kagan KO, To M, Tsoi E, Nicolaides KH. Preterm Birth: The Value of Sonographic Measurement of Cervical Length. BJOG. 2006 Dec;113
Suppl 3:52-6. [PubMed] [Crossref] 5. Fonseca EB, Celik E, Parra M, Singh M, Nicolaides KH. Fetal Medicine Foundation Second Trimester Screening Group. Progesterone and the risk of preterm birth among women with a short cervix. $N$ Engl J Med. 2007 Aug 2;357(5):462-9. [PubMed] [Crossref]

6. Romero R, Nicolaides $\mathrm{KH}$, Conde-Agudelo A, O'Brien JM, Cetingoz E, Da Fonseca E, et al. Vaginal Progesterone Decreases Preterm Birth $\leq 34$ Weeks of Gestation in Women With a Singleton Pregnancy and a Short Cervix: An Updated MetaAnalysis Including Data From the OPPTIMUM Study. Ultrasound Obstet Gynecol. 2016 Sep;48(3):308-17. [PubMed] [Crossref]

7. Romero R, Conde-Agudelo A, El-Refaie W, Rode L, Brizot ML, Cetingoz E, et al. Vaginal Progesterone
Decreases Preterm Birth and Neonatal Morbidity and Mortality in Women With a Twin Gestation and a Short Cervix: An Updated Meta-Analysis of Individual Patient Data. Ultrasound Obstet Gynecol. 2017 Mar;49(3):303314. [PubMed] [Crossref]

8. Houlihan C, Poon LCY, Ciarlo M, Kim E, Guzman ER, Nicolaides KH. Cervical Cerclage for Preterm Birth Prevention in Twin Gestation With Short Cervix: A Retrospective Cohort Study. Ultrasound Obstet Gynecol. 2016 Dec; 48(6):752-756. [PubMed] [Crossref]

9. Berghella V, Rafael TJ, Szychowski JM, Rust OA, Owen J. Cerclage for Short Cervix on Ultrasonography in Women With Singleton Gestations and Previous Preterm Birth: A Meta-Analysis. Obstet Gynecol. 2011 Mar;117(3):663-71. [PubMed] [Crossref] 
10. Thinkhamrop J, Hofmeyr GJ, Adetoro O, Lumbiganon P, Ota E. Antibiotic Prophylaxis During the Second and Third Trimester to Reduce Adverse Pregnancy Outcomes and Morbidity. Cochrane Database Syst Rev. 2015 Jan 26;1:CD002250. [PubMed] [Crossref]

11. Moutquin J-M. Classification and Heterogeneity of Preterm Birth. BJOG. 2003 Apr;110 Suppl 20:30-3. [PubMed] [Crossref]

12. Goldenberg RL, Culhane JF, Iams JD, Romero R. Epidemiology and Causes of Preterm Birth. Lancet. 2008 Jan 5;371(9606):75-84. [PubMed] [Crossref]

13. Romero R, Espinoza J, Kusanovic JP, Gotsch F, Hassan S, Erez $\mathrm{O}$, et al. The Preterm Parturition Syndrome. BJOG. 2006 Dec;113 Suppl 3(Suppl 3):17-42.[PubMed] [Crossref]

14. Romero R, Dey SK, Fisher SJ. Preterm Labor: One Syndrome, Many
Causes. Science. 2014 Aug 15; 345 (6198):760-5. [PubMed] [Crossref]

15. Celik E, To M, Gajewska K, Smith GCS, Nicolaides KH, FMFSTS Group. Cervical Length and Obstetric History Predict Spontaneous Preterm Birth: Development and Validation of a Model to Provide Individualized Risk Assessment. Ultrasound Obstet Gynecol. 2008 May;31(5):549-54. [PubMed] [Crossref]

16. HosnyAE-DMS, El-Khayat W, Kashef MT, Fakhry MN. Association Between Preterm Labor and Genitourinary Tract Infections Caused by Trichomonas Vaginalis, Mycoplasma Hominis, Gram-negative Bacilli, and Coryneforms. J Chin Med Assoc. 2017 Sep;80(9):575-81. [PubMed] [Crossref] 17. Espinoza J, Gonçalves LF, Romero R, Nien JK, Stites S, Kim YM, et al. The Prevalence and Clinical Significance of Amniotic Fluid 'Sludge' in Patients With Preterm Labor and Intact Membranes.Ultrasound Obstet Gynecol. 2005 Apr;25(4):346-52. [PubMed] [Crossref]

18. Bujold E, Pasquier J-C, Simoneau J, Arpin M-H, Duperron L, Morency A-M, et al. Intra-amniotic Sludge, Short Cervix, and Risk of Preterm Delivery. J Obstet Gynaecol Can. 2006 Mar;28(3):198-202. [PubMed] [Crossref]

19. Heath VC, Daskalakis G, Zagaliki A, Carvalho M, Nicolaides KH. Cervicovaginal Fibronectin and Cervical Length at 23 Weeks of Gestation: Relative Risk of Early Preterm Delivery. BJOG.2000 Oct;107(10): 1276-81. [PubMed] [Crossref]

20. Son M, Miller ES. Predicting preterm birth: Cervical length and fetal fibronectin. Semin Perinatol. 2017 Dec;41(8):445-451. [PubMed] [Crossref]

Please cite this article as: Ivanov ID. Measurement of the cervical lengthin 20-24weeks gestation, history of previous preterm laborand assessment of the vaginal microflora for bacterial vaginosis in the first trimester as a populational screening for preterm birth. J of IMAB. 2020 Jul-Sep;26(3):3302-3307. DOI: https://doi.org/10.5272/jimab.2020263.3302

Received: 09/07/2019; Published online: 31/08/2020

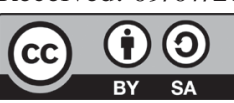

Address for correspondence:

Ivan D. Ivanov, Department of Obstetrics and Gynecolgy, Multiprofile Hospital for Active Treatment Trakia, Stara Zagora.

84, Patriarh Evtimii str., Stara Zagora 6000, Bulgaria

E-mail: iivanov_sz@yahoo.com 